\title{
Effects of age and pregnancy on the circulatory activin response of sheep to acute inflammatory challenge by lipopolysaccharide
}

\author{
L McClure, ${ }^{1,2}$, E O O'Connor ${ }^{1}$, S Hayward ${ }^{1}$, G Jenkin², \\ D W Walker ${ }^{2}$ and D J Phillips ${ }^{1}$ \\ ${ }^{1}$ Monash Institute of Reproduction and Development, Monash University, Clayton, Victoria, Australia \\ ${ }^{2}$ Department of Physiology, Monash University, Clayton, Victoria, Australia \\ (Requests for offprints should be addressed to D J Phillips, Centre for Molecular Reproduction \& Endocrinology, Monash Institute of Reproduction \& \\ Development, 27-31 Wright Street, Clayton 3168, Australia; Email: david.phillips@med.monash.edu.au)
}

\begin{abstract}
The release of activin $\mathrm{A}$ in response to intravenous injection of the bacterial cell-wall component lipopolysaccharide (LPS) was investigated in an ovine model of acute inflammatory challenge in newborn and adult sheep, and in non-pregnant and pregnant ewes. Neonatal lambs $(<20$ days of age) showed a quantitatively similar response in terms of circulating concentrations of activin A, its binding protein follistatin and the cytokine interleukin-6 compared with adult ewes challenged with an equivalent dose (300 $\mathrm{ng} / \mathrm{kg}$ bodyweight) of LPS. The fever response and plasma tumour necrosis factor- $\alpha$ release in response to LPS, however, were significantly $(P<0 \cdot 01)$ less in lambs than in the adult group. Pregnant ewes in the last trimester of gestation had similar responses to LPS, in all aspects measured, compared with their non-pregnant counterparts, apart from an ablated fever response. Although the adult and neonatal sheep responded to LPS, a similar response was not apparent in the fetal circulation, possibly
\end{abstract}

due to a protective effect of the placenta. A 10-fold increase in the dose of LPS (from $300 \mathrm{ng}$ to $3 \mu \mathrm{g} / \mathrm{kg}$ bodyweight) given to neonatal lambs elicited an increase in several cytokine responses measured, with a significant $(P<0 \cdot 05)$ increase in follistatin release. In contrast, the amount of activin released by the increased dose of LPS was similar to that invoked by the lower dose. The effect of tolerance to LPS was investigated by giving a second challenge of LPS 5 days after the initial injection. In all animals studied, there was an ablated $(P<0 \cdot 05)$ response to the subsequent LPS injection, apart from a similar temperature-response profile. These data provide further evidence that activin A concentrations in the bloodstream are acutely responsive to inflammatory challenge in postnatal life and suggest that the response forms a significant component of the innate immune system.

Journal of Endocrinology (2005) 185, 139-149

\section{Introduction}

The innate immune response is one of the most profound biological processes, as it affects almost all multicellular organisms at some stage of their development (Medzhitov 1998). Not only is it phylogenetically conserved, it is also of fundamental relevance during development and has received widespread attention based on its relevance to premature labour during human pregnancy (Gonçalves et al. 2002). Recently the growth factor, activin $A$, a member of the transforming growth factor- $\beta$ (TGF- $\beta$ ) superfamily of proteins (Chang et al. 2002), has been characterized as a new component in inflammatory processes (Jones et al. 2000, 2004). This protein was originally isolated as a non-steroidal feedback regulator of folliclestimulating hormone secretion, but is now known to have multiple functions besides the regulation of gonadal activity (Woodruff 1998).
The release of activin A into the bloodstream in response to an acute inflammatory challenge occurs rapidly, within minutes of exposure to agents such as the bacterial cell-wall component lipopolysaccharide (LPS; Jones et al. 2004). The response is more rapid than that seen for some of the key pro-inflammatory cytokines, such as tumour necrosis factor- $\alpha$ (TNF- $\alpha$ ) or interleukin-6 (IL-6), and appears distinctly earlier than the release of follistatin, the high-affinity binding protein for activin that has neutralizing properties (Jones et al. 2000, 2004). However, the function of the activin release has not been delineated, except that activin A has both pro- and anti-inflammatory properties depending on the temporal and functional context (Phillips 2003). Given that the activin response to inflammatory mediators has only been investigated using in vitro approaches or in mature animals, it is not known if this mechanism pertains only in adult life or is indeed 
a component of an innate immune response present in immature or fetal animals.

This series of studies explored the hypothesis that the release of activin $\mathrm{A}$ into the bloodstream following acute inflammatory challenge is a core component of the innate immune response. As much of the previous work in this area has been carried out in a sheep model of systemic LPS exposure (Jones et al. 2000, 2004), the response in adult ewes was compared with that in neonatal lambs and in fetuses where LPS was administered into the maternal circulation. Additionally, the response was characterized in neonates where the dose of LPS was increased 10-fold. Two other aspects of the activin response were explored. For some time now, pregnancy has been thought of as a state in which the maternal adaptive immune responses, particularly at the maternal-fetal interface, are suppressed, yet paradoxically fever and the innate immune response are activated (Sacks et al. 1999). Of relevance is that the fetus appears protected by the placenta in some aspects of the inflammatory response when the mother is challenged with LPS (Grigsby et al. 2003). Therefore the activin response in pregnant versus non-pregnant ewes was compared. Finally, whether the activin response was subject to tolerance, whereby there is a hyporesponsive state to subsequent challenge by LPS following an initial exposure (Cross 2002), was also investigated.

\section{Materials and Methods}

\section{Animals and catheterization details}

All studies were performed in Border Leicester-Merino cross-bred animals and were approved by the Animal Ethics Committee of the Department of Physiology, Monash University, Australia. Adult ewes were housed in individual metabolism cages, fed a diet of chopped lucerne hay once daily and had free access to tap water. Lambs between 12 and 15 days of age were housed with their mothers in lambing pens. To provide a similar endocrine background between individuals, adult non-pregnant ewes underwent ovariectomy approximately 1 week before the initial exposure to LPS. At surgery, they also had sampling catheters inserted into the external jugular vein and the carotid artery. Patency of catheters was maintained with $0.9 \%$ saline solution containing $37 \mathrm{mM}$ EDTA (BDH Laboratory Supplies, Poole, Dorset, UK). This anticoagulant does not affect circulating concentrations of activin A or follistatin, unlike heparin (Klein et al. 1996). Lambs had an indwelling jugular catheter inserted at surgery as described previously (Billiards et al. 2002). Pregnant ewes had surgery at 124-126 days of gestation (day $145=$ term) for the placement of catheters essentially as described previously (Grigsby et al. 2003). Briefly, maternal jugular vein, carotid artery, intraamniotic fluid, fetal carotid artery and jugular vein catheters were inserted. A thermocouple temperature probe was placed in the fetal neck next to the carotid artery. The calcium-chelating properties of EDTA make it unsuitable for in vivo use in fetuses and young lambs. Therefore, sterile saline solution $(0.9 \% \mathrm{NaCl})$ containing $5000 \mathrm{IU}$ heparin/ml (Pharmacia, Perth, Australia) was used to keep the catheters patent. At least $12 \mathrm{~h}$ before the commencement of an experiment, however, fetal and neonatal catheters were flushed with non-heparinized saline solution to avoid any artifactual increases in plasma activin or follistatin concentrations.

\section{Experimental details}

All animals, apart from fetuses, were treated i.v. with LPS (Escherichia coli serotype 0127:B8; Sigma, St Louis, MO, USA). The adult ewes and lambs were weighed the day before the experiments commenced. Non-pregnant adult ewes $(n=7)$, pregnant ewes $(n=5)$ and lambs $(n=5)$ were treated with a bolus dose of $300 \mathrm{ng}$ LPS $/ \mathrm{kg}$ bodyweight. A further group of lambs $(n=4)$ and two pregnant ewes were given a higher dose of $3 \mu \mathrm{g} / \mathrm{kg}$ LPS. Body temperature was recorded using a rectal digital thermometer for the ewes and lambs, and fetal temperature recorded using a thermistor probe implanted next to the carotid artery at surgery. Blood samples from fetuses, lambs or adults and the amniotic fluid of some pregnant ewes were collected from the indwelling catheters $1 \mathrm{~h}$ before and at the time of LPS injection. Samples were collected at half-hourly intervals up to $5 \mathrm{~h}$ after the LPS injection, then at 6,9 , 12 and $24 \mathrm{~h}$ thereafter. Blood gases $\left(\mathrm{PO}_{2}, \mathrm{PCO}_{2}\right)$ and $\mathrm{pH}$ were measured in freshly drawn arterial blood samples using an ABL5 blood gas analyzer and OSM2 Hemoximeter (Radiometer, Copenhagen, Denmark; data not shown). Five days after the initial LPS challenge, animals received a second LPS injection with an identical dose and blood-sampling regime to that of the first. In all instances, blood or amniotic fluid samples were spun on a benchtop centrifuge for $5 \mathrm{~min}$ at $3000 \mathrm{~g}$. The resultant plasma or amniotic fluid supernatants were stored at $-20{ }^{\circ} \mathrm{C}$ until assayed.

\section{Assays}

Plasma activin A levels were determined as described previously using an enzyme-linked immunosorbent assay (ELISA; Knight et al. 1996). The assay measures 'total' activin $\mathrm{A}$ - that is, both free and bound - and has been validated extensively for sheep plasma and amniotic fluid (Jenkin et al. 2001a). The assay standard was human recombinant activin A (Biotech Australia Pty. Ltd; Robertson et al. 1992). The mean assay sensitivity was $0.01 \mathrm{ng} / \mathrm{ml}$, and the mean intra- and inter-assay coefficients of variation $(\mathrm{CVs})$ were both $<9 \%$.

Follistatin was measured by a RIA as described previously (Phillips et al. 1996), which also measures both free and bound forms. The assay uses purified 
heterologous bovine follistatin as standard and iodinated bovine follistatin as tracer. The assay sensitivity was $2.3 \mathrm{ng} / \mathrm{ml}$ and the intra- and inter-assay CVs were both $<8 \%$.

TNF- $\alpha$ was measured by an ELISA as described previously (Jones et al. 2000) with minor modifications. The standard was ovine recombinant TNF- $\alpha$ (Centre for Animal Biotechnology, University of Melbourne, Australia), the assay sensitivity was $0.03 \mathrm{ng} / \mathrm{ml}$, and the intra- and inter-assay CVs were both $<9 \%$.

IL-6 concentrations were measured by ELISA as described previously (Jones et al. 2000), using antibodies specific to ovine IL-6 (Epitope Technologies, Melbourne, Australia). The standard was ovine recombinant IL-6 (Centre for Animal Biotechnology), the sensitivity was $0.02 \mathrm{ng} / \mathrm{ml}$ and the intra- and inter-assay CVs were both $<14 \%$.

\section{Data analysis}

Data were analysed statistically using GraphPad version 2 (GraphPad Software, San Diego, CA, USA). This package was also used to calculate the area under the curve (AUC) function. Where appropriate, data were log-transformed before analysis to correct for heterogeneity of variances. Parameters between groups of animals were analysed by one-way analysis of variance (ANOVA), followed by the Newman-Keuls post-hoc test, where appropriate. Comparisons between two different groups were analysed using Student's $t$-test and for comparisons within the same group of animals paired Student's $t$-test was used.

\section{Results}

Response to LPS in adult non-pregnant versus neonatal lambs

Adult ovariectomized ewes exhibited a classical fever response to $300 \mathrm{ng} / \mathrm{kg}$ LPS (Fig. 1A). The body temperature was significantly $(P<0.05)$ elevated for $6 \mathrm{~h}$, after which time it returned to pre-treatment levels. Measurement of plasma concentrations of activin A, follistatin, IL-6 and TNF- $\alpha$ showed typical responses to LPS challenge (Fig. 1B-E). When an identical per-bodyweight dose of LPS was administered to neonatal lambs, they too showed an increase in body temperature and an increase in the various blood factors measured (Fig. 1A-E). The response was similar to that of the adult ewes, except that the increases of temperature $(P<0 \cdot 01)$, plasma follistatin $(P<0.05)$ and TNF- $\alpha(P<0.05)$ responses were less than for the ewes, as assessed by AUC (Table 1). Of interest was that the basal plasma concentrations of activin A differed between adults and neonates before LPS treatment, with the lambs having significantly $(P<0 \cdot 001)$ higher concentrations $(0.137 \pm 0.007 \mathrm{ng} / \mathrm{ml}$, mean \pm S.E.M. $)$ compared with the adult ewes $(0 \cdot 015 \pm 0 \cdot 002 \mathrm{ng} / \mathrm{ml})$, respectively.
Response to LPS in adult non-pregnant versus pregnant ewes

The effect of pregnancy on the response to LPS administration was assessed in pregnant ewes at 130-135 days of gestation, with comparison against the ovariectomized group of ewes. Both groups of animals had a qualitatively similar response to LPS in terms of fever and plasma concentrations of activin A, follistatin, IL- 6 and TNF- $\alpha$ (Fig. 2), but the pyrexia was significantly $(P<0 \cdot 01)$ less in the pregnant animals (Table 1). All other parameters measured were not statistically different between the two groups in response to LPS challenge. Similar to the neonatal lambs, however, pregnant adult ewes had significantly $(P<0 \cdot 001)$ higher concentrations of activin A before LPS administration compared with their non-pregnant counterparts $(0.05 \pm 0.007$ and $0.015 \pm 0.002 \mathrm{ng} / \mathrm{ml}$, respectively).

\section{Maternal versus fetal response to LPS when administered to} the mother

To determine if LPS given maternally had effects on the fetal-placental environment, LPS was administered i.v. at $300 \mathrm{ng} / \mathrm{kg}$ bodyweight to pregnant ewes. As mentioned above, the adult ewes had a profound fever response and changes in plasma concentrations of activin A, follistatin, IL-6 and TNF- $\alpha$ (Fig. 3). Fetal body temperature (Fig. 3A) was also elevated in response to maternal LPS challenge and the profile was similar to that observed in the mother. Nevertheless, there was little effect on fetal plasma concentrations of activin A, follistatin, IL-6 or TNF- $\alpha$ following LPS (Fig. 3B-E). This was despite significantly $(P<0 \cdot 05)$ higher pre-treatment concentrations of activin $\mathrm{A}$ in the fetuses compared with maternal plasma concentrations $(0 \cdot 101 \pm 0.019$ versus $0.05 \pm$ $0.007 \mathrm{ng} / \mathrm{ml})$. There was a minor but not statistically significant increase in fetal plasma follistatin concentrations (Fig. 3C) and three out of five fetuses exhibited elevated activin A concentrations at the 24-h timepoint (Fig. 3B). In general, the same fetuses that had an elevated activin level at $24 \mathrm{~h}$ were those that also had elevated follistatin concentrations. Similar to the fetal circulating concentrations, there was little change in amniotic fluid concentrations of either activin A or follistatin with maternal i.v. LPS challenge. The mean ( \pm S.E.M.) concentration of activin A in amniotic fluid before LPS challenge was $2.93 \pm 1.30 \mathrm{ng} / \mathrm{ml}$ and for follistatin $10.5 \pm 1.6 \mathrm{ng} / \mathrm{ml}$. These concentrations did not alter by more than $25 \%$ over the 24-h period following LPS administration. To ascertain if a response in the fetal or amniotic fluid compartments was apparent if the dose of LPS was increased, two pregnant ewes were injected i.v. with $3 \mu \mathrm{g} / \mathrm{kg}$ LPS. Similar to the $300 \mathrm{ng} / \mathrm{kg}$ dose, there were no apparent effects on fetal plasma activin A, IL- 6 or TNF- $\alpha$ concentrations, nor on amniotic fluid activin A or follistatin levels (data not shown). In both fetuses, however, there were 

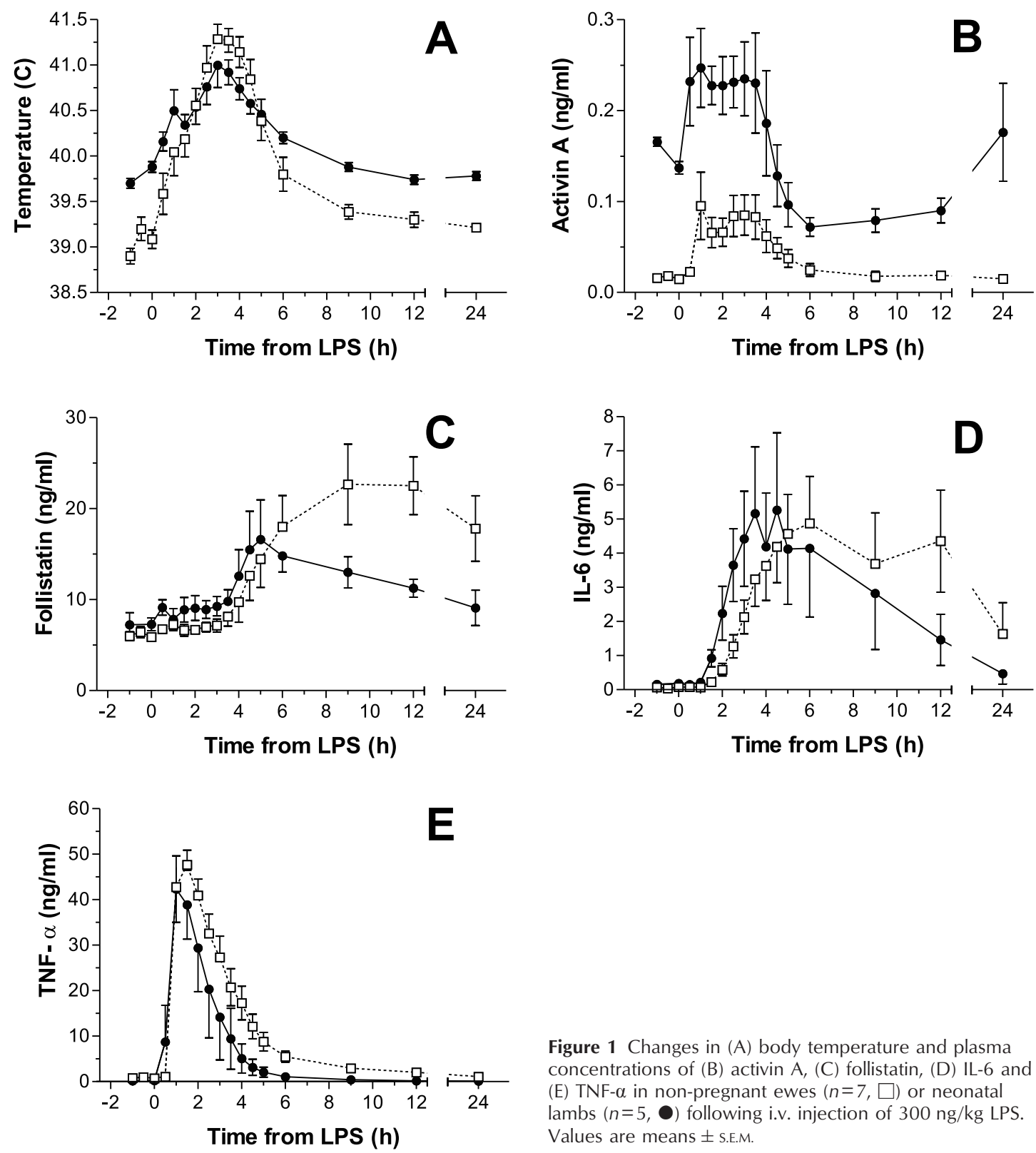

Figure 1 Changes in (A) body temperature and plasma concentrations of (B) activin A, (C) follistatin, (D) IL-6 and (E) TNF- $\alpha$ in non-pregnant ewes $(n=7, \square)$ or neonatal lambs $(n=5$, O) following i.v. injection of $300 \mathrm{ng} / \mathrm{kg}$ LPS. Values are means \pm S.E.M.

elevations in fetal plasma follistatin concentrations similar to those seen with the lower dose of LPS.

Response to LPS in neonatal lambs comparing two different doses

To determine if the response to LPS was dependent on the dose used, groups of neonatal lambs were challenged with either $300 \mathrm{ng} / \mathrm{kg}$ LPS or a 10-fold-higher dose of $3 \mu \mathrm{g} / \mathrm{kg}$ LPS (Fig. 4 and Table 1). Both doses induced a fever response and increases in plasma concentrations of the factors measured. While statistically significant
$(P<0 \cdot 05)$ only for follistatin (Table 1$)$, the other factors had increased AUC responses to the higher dose of LPS, with the exception of a reduced response for activin A.

\section{Differing response to LPS following an initial versus a} subsequent challenge

Whether the response to LPS was altered by repetition of the challenge was assessed when animals were treated with identical doses of LPS after an interval of 5 days. A consistent effect in all groups (non-pregnant adults, pregnant adults and neonatal lambs) was that the overall 
Table 1 Responses to LPS at the doses indicated, measured as AUC, for various parameters for non-pregnant ewes, pregnant ewes and neonatal lambs. Data are means \pm S.E.M., analysed by one-way ANOVA with differences between groups detected by the Newman-Keuls post hoc test

\begin{tabular}{|c|c|c|c|c|}
\hline & \multicolumn{4}{|l|}{ AUC } \\
\hline & $\begin{array}{l}\text { Non-pregnant ewes } \\
(n=7) 300 \mathrm{ng} / \mathrm{kg} \text { LPS }\end{array}$ & $\begin{array}{l}\text { Pregnant ewes } \\
(n=5) 300 \mathrm{ng} / \mathrm{kg} \text { LPS }\end{array}$ & $\begin{array}{l}\text { Neonatal lambs } \\
(n=5) 300 \mathrm{ng} / \mathrm{kg} \text { LPS }\end{array}$ & $\begin{array}{l}\text { Neonatal lambs } \\
(n=4) 3 \mu \mathrm{g} / \mathrm{kg} \text { LPS }\end{array}$ \\
\hline \multicolumn{5}{|l|}{ Parameter } \\
\hline Temperature $\left({ }^{\circ} \mathrm{C} / \mathrm{h}\right)$ & $12 \cdot 93 \pm 1 \cdot 89$ & $4 \cdot 05 \pm 0.68^{* *}$ & $4.63 \pm 1.05^{* *}$ & $7 \cdot 96 \pm 1 \cdot 62$ \\
\hline Activin A (ng/ml/h) & $0 \cdot 42 \pm 0 \cdot 13$ & $0 \cdot 38 \pm 0.09$ & $0.67 \pm 0.21$ & $0 \cdot 34 \pm 0 \cdot 10$ \\
\hline Follistatin $(\mathrm{ng} / \mathrm{ml} / \mathrm{h})$ & $295 \cdot 7 \pm 72 \cdot 8^{*}$ & $235 \cdot 6 \pm 19 \cdot 6$ & $93 \cdot 6 \pm 18 \cdot 9$ & $221 \cdot 5 \pm 41 \cdot 3^{*}$ \\
\hline IL-6 (ng/ml/h) & $69 \cdot 6 \pm 24 \cdot 0$ & $41 \cdot 8 \pm 10 \cdot 1$ & $42 \cdot 4 \pm 21 \cdot 6$ & $120 \cdot 5 \pm 35 \cdot 9$ \\
\hline TNF- $\alpha(\mathrm{ng} / \mathrm{ml} / \mathrm{h})$ & $145 \cdot 3 \pm 21 \cdot 1^{*}$ & $130 \cdot 9 \pm 13 \cdot 1^{*}$ & $71 \cdot 5 \pm 24.9$ & $133 \cdot 5 \pm 11 \cdot 3$ \\
\hline
\end{tabular}

Within a parameter, ${ }^{*} P<0 \cdot 05$ compared with neonates given $300 \mathrm{ng} / \mathrm{kg} \mathrm{LPS},{ }^{* *} P<0 \cdot 01$ compared with non-pregnant ewes.

response to LPS was attenuated with the second challenge. Profiles from the non-pregnant group are presented in Fig. 5 and the peak responses and AUC values are shown for all groups in Table 2. While there was no significant decrease in the fever response, in all other parameters assessed there was a decrease in the peak plasma concentrations (with the exception of activin A) and in the AUC profiles determined for activin A, follistatin, TNF- $\alpha$ and IL-6.

\section{Discussion}

The data presented in this study provide significant new insights into the rapid release of activin $\mathrm{A}$ into the circulation following immune activation and lend further support to the concept that activin $\mathrm{A}$ is an important component of the innate immune response, at least in higher mammals. The experiments show that the activin response is functional at least as early as the first days of post-natal life and that while there is a maternal response during pregnancy, the fetus appears protected from many of the inflammatory changes because of the placental barrier. Over the limited dose range tested, the substantial release of activin in response to LPS inflammatory stimulus did not appear to be dose-dependent, although the activin response to subsequent challenge appeared to be reduced, consistent with the development of tolerance to this endotoxin.

While the release of activin A into the circulation following inflammatory challenge by agents such as LPS has been documented by us previously (Jones et al. 2000, 2004), this has been characterized only in adult subjects. A major aim of the present study was to establish if this response mechanism was operant only in mature individuals and, as such, developed in post-natal life. When post-natal lambs were challenged with LPS, however, they displayed a typical pyrogenic response and importantly a qualitatively similar release of activin A, follistatin and pro-inflammatory cytokines to that of adults. On this basis, it appears that, similar to other aspects of innate immunity, the activin component is fully functional in the immature animal. When administered at the same per-bodyweight dose to immature animals, the response to LPS was less in most of the parameters measured compared with adults. This is consistent with previous studies suggesting that early neonates are less responsive to LPS compared with older immature animals or in adults (Bech-Jansen et al. 1972, Goelst et al. 1992, Coceani et al. 1995). Of interest was that the basal circulating concentrations of activin A were significantly $(P<0 \cdot 001)$ higher in the neonate group compared with the adults. As shown in Fig. 1, the levels of activin following the initial 'surge' after LPS treatment then became lower than pre-treatment concentrations, but had returned to preLPS levels after $24 \mathrm{~h}$. The significance of this biphasic effect for the neonate is not known and nor, as far as we can ascertain, have the concentrations of activin A been reported previously for neonates and found to be higher than in adults.

The effect of pregnancy on the release of activin A following LPS challenge was explored in sheep during the last trimester. This is particularly relevant given the large body of literature suggesting that pregnancy is an endocrine state in which the adaptive immune response is suppressed to avoid maternal rejection of the developing fetus, but where aspects of the innate immune response are sensitized (Sacks et al. 1999). Pregnant animals had a similar response to LPS challenge compared with their non-pregnant counterparts in all aspects measured, except for a reduced fever response. Therefore, there appeared to be little effect of pregnancy on the quantitative response of activin A, follistatin and the pro-inflammatory cytokines measured following immune activation. Nevertheless, the basal concentrations of activin A were higher in pregnant ewes than in the non-pregnant group, consistent with observations that circulating maternal activin levels increase during pregnancy and particularly in the last trimester (Fowler et al. 1998, Schneider-Kolsky et al. 2000, Muttukrishna 2001). On balance, while the current study was not explicitly formulated to address the question of 

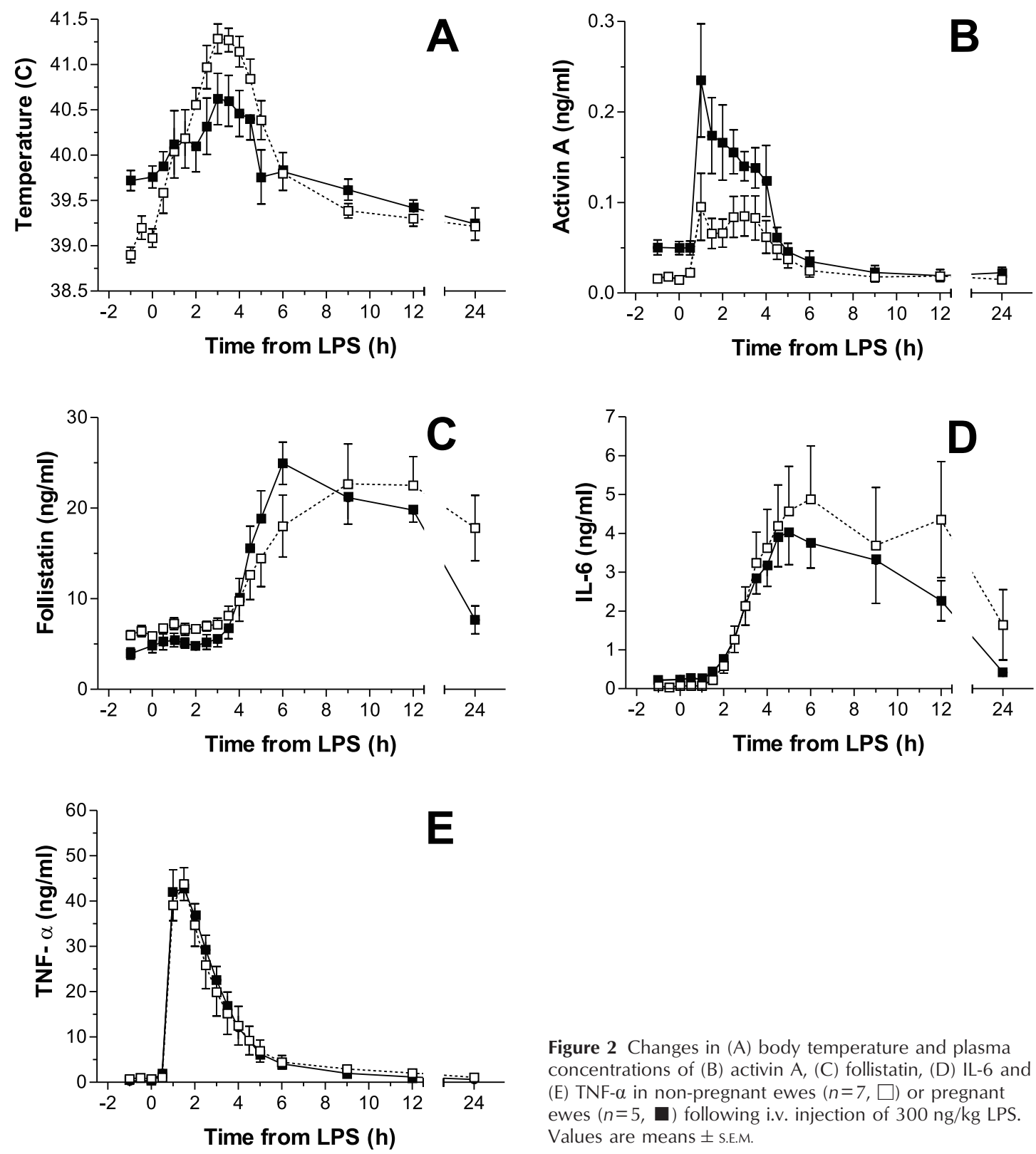

Figure 2 Changes in (A) body temperature and plasma concentrations of (B) activin A, (C) follistatin, (D) IL-6 and (E) TNF- $\alpha$ in non-pregnant ewes $(n=7, \square)$ or pregnant ewes $(n=5, \mathbf{a})$ following i.v. injection of $300 \mathrm{ng} / \mathrm{kg}$ LPS. Values are means \pm S.E.M.

heightened innate immunity or otherwise during pregnancy, it therefore suggests that the activin response to inflammatory challenge is manifested regardless of the pregnancy status of an individual.

While it is clear that the maternal inflammatory system is able to respond to endotoxin challenge during pregnancy, the fetus appears to be protected from the maternal response. The experiments reported here showed that, despite robust temperature, activin A, follistatin and cytokine responses in the mother, with the exception of temperature concomitant increases in the fetal compartment were not seen. Fetal temperature did rise simul-

taneously with that of the mother, consistent with the idea that most heat is lost from the fetal compartment across the placenta into maternal blood (Schröder \& Power 1997). However, in terms of TNF- $\alpha$ and IL-6 concentrations in the fetus, there were no significant changes in the 24-h period following LPS treatment. The data for activin A and follistatin were also statistically non-significant, although some of the fetuses had higher activin concentrations at the 24-h timepoint and circulating fetal follistatin concentrations increased in some animals between 8 and $24 \mathrm{~h}$ after LPS was administered to the mother. Whether this is a true effect is yet to be established and it 

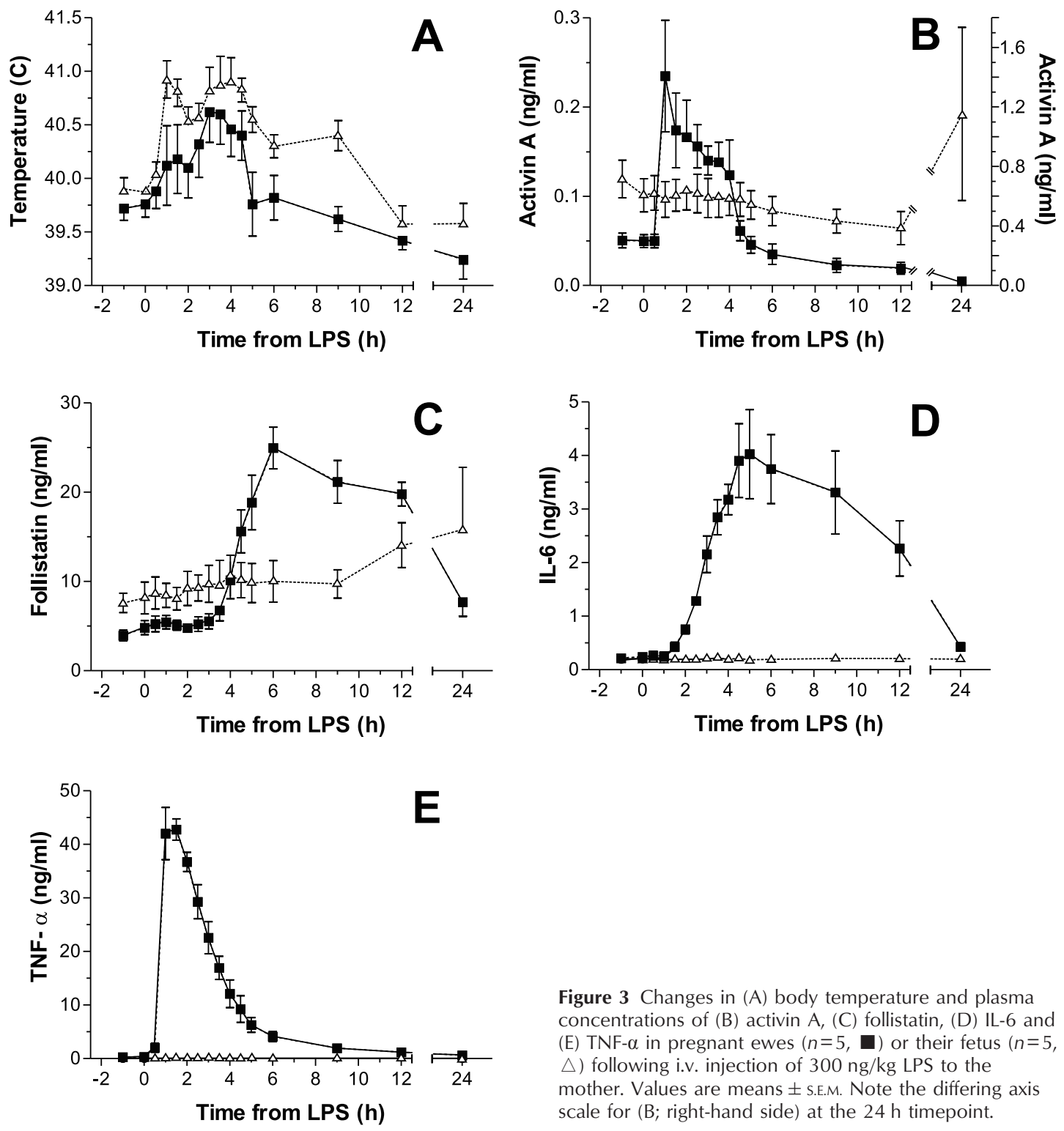

Figure 3 Changes in (A) body temperature and plasma concentrations of (B) activin A, (C) follistatin, (D) IL-6 and (E) TNF- $\alpha$ in pregnant ewes $(n=5, \mathbf{\square})$ or their fetus $(n=5$, $\triangle$ ) following i.v. injection of $300 \mathrm{ng} / \mathrm{kg}$ LPS to the mother. Values are means \pm S.E.M. Note the differing axis scale for (B; right-hand side) at the $24 \mathrm{~h}$ timepoint.

is not known if direct stimulation of the fetus by inflammatory challenges such as LPS will result in activin A and follistatin being released into the fetal circulation. Overall, however, the current data suggest that neither LPS nor the cytokines are able to cross the placental barrier, and that the placenta acts to contain the maternal immune response and ensure that inappropriate and unnecessary activation of the fetal immune system is not a consequence. This is consistent with a recent study showing that maternal activation only results in certain components, such as cortisol and prostaglandin $\mathrm{E}_{2}$, responding in the fetal compartment (Grigsby et al. 2003). Interestingly, the resting concentrations of activin $\mathrm{A}$ in the fetal and maternal circulations were significantly different, with fetal levels

being approximately double that in the mother. This is in contrast to published findings in human pregnancies where maternal activin A concentrations appear higher (Florio et al. 1999, Schneider-Kolsky et al. 2002), but consistent with those shown previously in the sheep (Jenkin et al. 2001b) where fetal levels are higher. The reasons behind this apparent dichotomy between the two species are unclear, but may involve the different placentation types, with cotyledonary in the sheep versus discoid in the human affecting placental transfer of activin, as discussed by Loose and colleagues (Loose et al. 2004).

The magnitude of the activin response to LPS challenge was investigated in this study by evaluating the effects of a 10 -fold difference in the dose of LPS used. In neonatal 

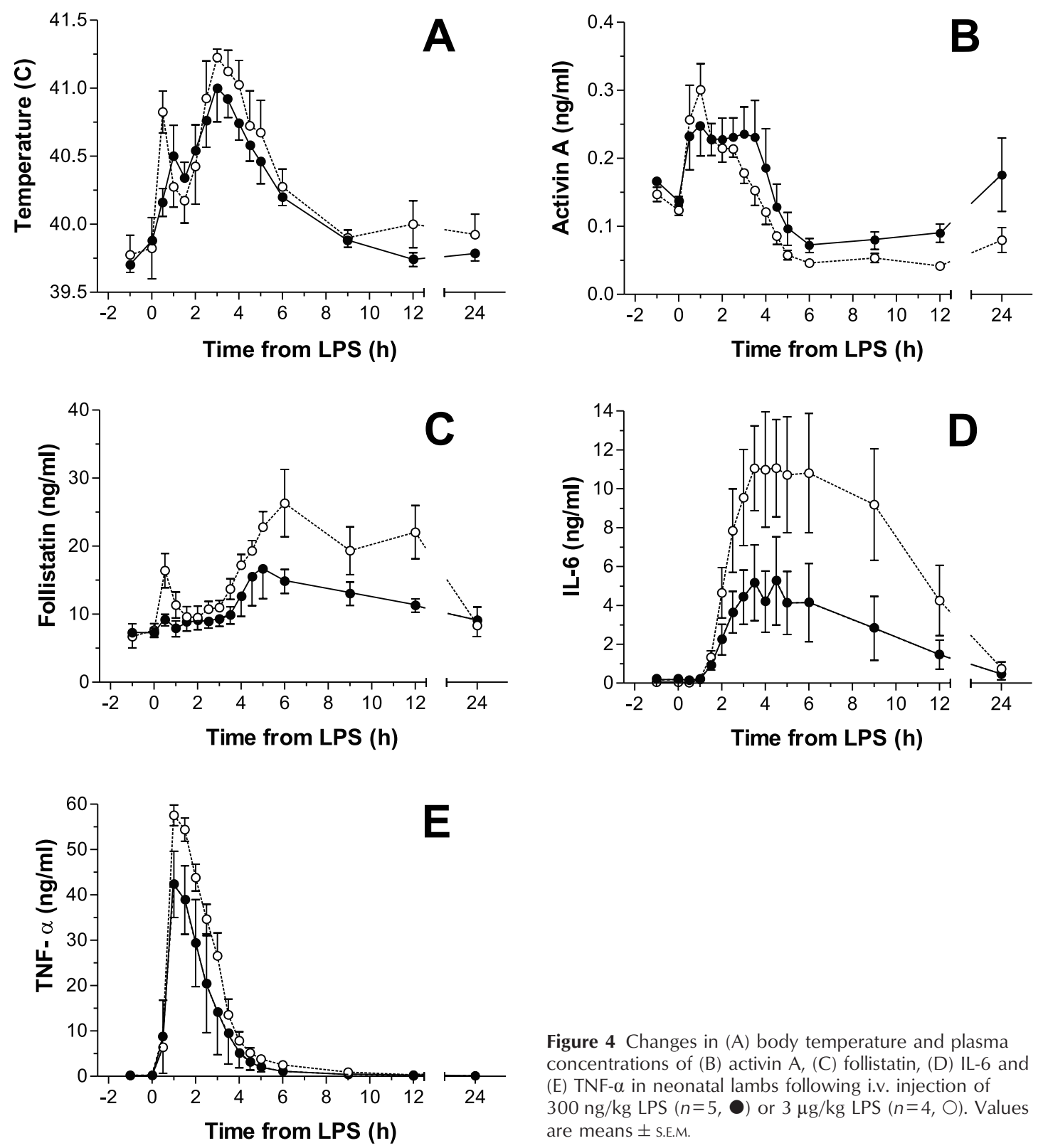

Figure 4 Changes in (A) body temperature and plasma concentrations of (B) activin A, (C) follistatin, (D) IL-6 and (E) TNF- $\alpha$ in neonatal lambs following i.v. injection of $300 \mathrm{ng} / \mathrm{kg}$ LPS $(n=5,0)$ or $3 \mu \mathrm{g} / \mathrm{kg}$ LPS $(n=4, \bigcirc)$. Values are means \pm S.E.M.

lambs subjected to this paradigm, although there were increases in the response to the higher LPS dose in most parameters measured, the only statistically significant $(P<0 \cdot 05)$ increase was in the amount of follistatin released. An enhancement in cytokine release in response to increasing doses of LPS has been reported for larger mammalian species but this may be dependent on the cytokine assessed (LeMay et al. 1990, Gerros et al. 1993, Mullington et al. 2000, Haudek et al. 2003). The notable exception to the overall effect on cytokine responses was that at the higher dose of LPS employed $(3 \mu \mathrm{g} / \mathrm{kg})$, there was less activin A released, although this was not statisti-

cally different from that of the lower dose of LPS used $(300 \mathrm{ng} / \mathrm{kg})$. Of relevance is that at an intermediate dose (1 $\mu \mathrm{g} / \mathrm{kg}$; Jones et al. 2000, 2004) adult animals appear to have a qualitatively similar activin A release compared with the $300 \mathrm{ng} / \mathrm{kg}$ dose used in the present study for both the adults and neonatal animals. Therefore, whether the activin A release in response to graded doses of LPS challenge is part of an all-or-none effect, or is to some extent dose-dependent, should be the subject of future studies.

A reduced responsiveness to subsequent LPS challenge, coined endotoxin tolerance, has been the subject of recent 

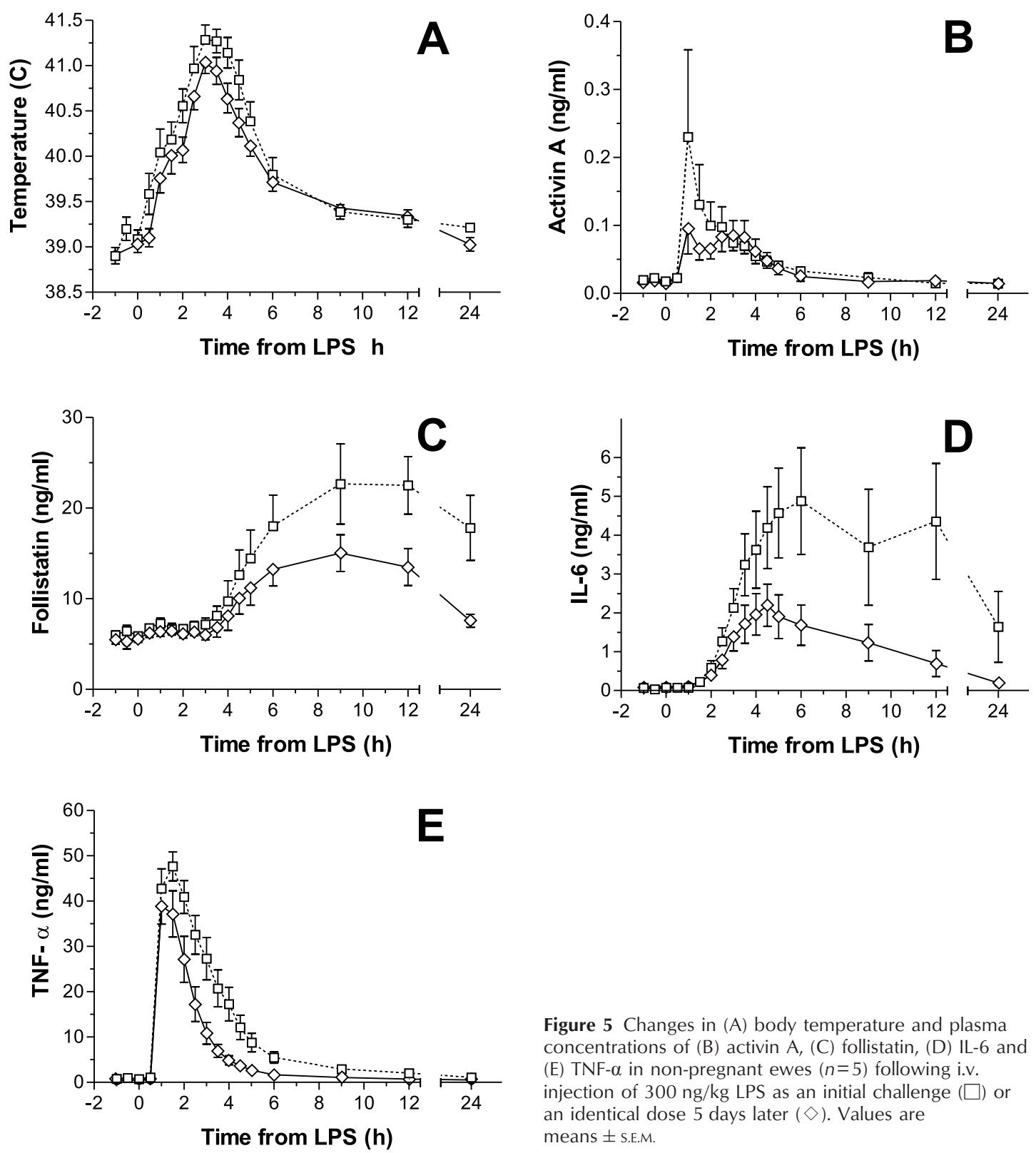

Figure 5 Changes in (A) body temperature and plasma concentrations of (B) activin A, (C) follistatin, (D) IL-6 and (E) TNF- $\alpha$ in non-pregnant ewes $(n=5)$ following i.v. injection of $300 \mathrm{ng} / \mathrm{kg}$ LPS as an initial challenge $(\square)$ or an identical dose 5 days later $(\diamond)$. Values are means \pm S.E.M.

interest in that it resembles the situation that often arises in human patients with sepsis or non-infectious systemic inflammatory response syndrome (SIRS) brought about by surgery and acute trauma of various causes (Cavaillon et al. 2003). On this basis, it was investigated whether the release of activin A into the circulation was subject to a tolerance-like effect; that is, was reduced in response to a second LPS challenge. Similar to the ablated effect on TNF- $\alpha$ and IL- 6 , the response of both activin A and follistatin was reduced following LPS treatment of an identical dose administered 5 days after an initial challenge. The nature of how these proteins form part of the

tolerance mechanism has not been elucidated; tolerance is readily demonstrable in mature sheep (Whyte et al. 1989) and is also presumed to occur in immature animals. Of interest will be to establish if the diminished release of activin/follistatin is subject to a recovery in responsiveness, as in rats there is an initial refractory period to repeated LPS stimulation which disappears after some weeks and after which a full response to LPS is observed again (Sanchez-Cantu et al. 1989).

The role of activin $\mathrm{A}$ and its release during inflammatory challenge is still largely unclear. In vitro studies have shown that activin can have both pro- and anti- 
Table 2 Responses to an initial (\#1) or subsequent (\#2) challenge to LPS, measured as peak temperature, peak concentration or AUC, for various parameters for non-pregnant ewes, pregnant ewes and neonatal lambs. Data are means \pm S.E.M., analysed by paired Student's t-test

\begin{tabular}{|c|c|c|c|c|}
\hline & \multicolumn{2}{|c|}{ Peak response $\left({ }^{\circ} \mathrm{C}\right.$ or $\left.\mathrm{ng} / \mathrm{ml}\right)$} & \multicolumn{2}{|c|}{ AUC $\left({ }^{\circ} \mathrm{C} / \mathrm{h}\right.$ or $\left.\mathrm{ng} / \mathrm{ml} / \mathrm{h}\right)$} \\
\hline & LPS challenge \#1 & LPS challenge \#2 & LPS challenge \#1 & LPS challenge \#2 \\
\hline \multicolumn{5}{|l|}{ Parameter } \\
\hline Temperature & $41 \cdot 2 \pm 0 \cdot 1$ & $41 \cdot 1 \pm 0 \cdot 1$ & $7 \cdot 89 \pm 1 \cdot 11$ & $7 \cdot 70 \pm 1 \cdot 27$ \\
\hline Activin A & $0 \cdot 27 \pm 0 \cdot 04$ & $0 \cdot 20 \pm 0 \cdot 02$ & $0 \cdot 45 \pm 0 \cdot 07$ & $0 \cdot 25 \pm 0 \cdot 05^{*}$ \\
\hline Follistatin & $23 \cdot 6 \pm 2 \cdot 2$ & $17 \cdot 8 \pm 1 \cdot 4^{* *}$ & $204 \cdot 5 \pm 31 \cdot 4$ & $113 \cdot 2 \pm 15 \cdot 1^{* * *}$ \\
\hline IL-6 & $6 \cdot 6 \pm 1 \cdot 1$ & $3 \cdot 3 \pm 0 \cdot 4^{* * *}$ & $69 \cdot 5 \pm 13 \cdot 9$ & $20 \cdot 4 \pm 3 \cdot 5^{* *}$ \\
\hline TNF- $\alpha$ & $48 \cdot 2 \pm 2 \cdot 4$ & $40 \cdot 4 \pm 2 \cdot 3^{* *}$ & $122 \cdot 0 \pm 11 \cdot 3$ & $75 \cdot 2 \pm 7 \cdot 5^{* * *}$ \\
\hline
\end{tabular}

${ }^{*} P<0 \cdot 05,{ }^{*} P<0 \cdot 01,{ }^{* *} P<0 \cdot 001$ compared with the LPS challenge \#1.

inflammatory functions (Phillips 2003), with its effects likely to be dependent on the cell types participating in the response and the inflammatory networks acting at that particular phase. The source of activin during inflammatory processes may be immune cell types or endothelial cells lining the vasculature, but further work is required to confirm this proposition. Nevertheless, the current studies highlight new aspects in delineating the activin response in a widely accepted model of acute inflammatory challenge. In summary, these findings demonstrate that activin forms part of a coordinated inflammatory reaction that is present in development from at least the first days of post-natal life. During pregnancy, the placenta appears to act as a barrier to protect the fetus from the effects of the maternal responses. Of interest was that, at least at the doses tested, the release of activin to LPS was not dose-dependent and possibly is part of an all-or-none response. Finally, the activin and follistatin components had ablated responses to subsequent LPS challenge, suggesting that they form part of the well-known hyporesponsive tolerance mechanism of repeated immune activation.

\section{Acknowledgements}

We thank Alex Satragno for surgical assistance and Jean-Pierre Scheerlinck for provision of TNF- $\alpha$ and IL-6 immunoassay reagents. The authors declare that there is no conflict of interest that would prejudice the impartiality of this scientific work.

\section{Funding}

This work was funded by the NHMRC of Australia (program grant 143786).

\section{References}

Bech-Jansen P, Brinkman CR III, Johnson GH \& Assali NS 1972 Circulatory shock in pregnant sheep. II. Effects of endotoxin on fetal and neonatal circulation. American Journal of Obstetrics and Gynecology 113 37-43.
Billiards SS, Walker DW, Canny BJ \& Hirst JJ 2002 Endotoxin increases sleep and brain allopregnanolone concentrations in newborn lambs. Pediatric Research 52 892-899.

Cavaillon J-M, Adrie C, Fitting C \& Adib-Conquy M 2003 Endotoxin tolerance: is there a clinical relevance? Journal of Endotoxin Research 9 101-107.

Chang H, Brown CW \& Matzuk MM 2002 Genetic analysis of the mammalian transforming growth factor- $\beta$ superfamily. Endocrine Reviews 23 787-823.

Coceani F, Bishai I, Engelberts D, House RV \& Adamson SL 1995 Response of newborn and adult sheep to pyrogens: relation between fever and eicasanoid changes. Brain Research $\mathbf{7 0 0}$ 191-204.

Cross AS 2002 Endotoxin tolerance-current concepts in historical perspective. Journal of Endotoxin Research 8 83-98.

Florio P, Benedetto C, Luisi S, Santuz M, Di Carlo C, Marozio L, Genazzani AR \& Petraglia F 1999 Activin A, inhibin A, inhibin B and parturition: changes of maternal and cord serum levels according to the mode of delivery. British Journal of Obstetrics and Gynaecology 106 1061-1065.

Fowler PA, Evans LW, Groome NP, Templeton A \& Knight PG 1998 A longitudinal study of maternal serum inhibin-A, inhibin-B, activin- $\mathrm{A}$, activin- $\mathrm{AB}$, pro- $\alpha \mathrm{C}$ and follistatin during pregnancy. Human Reproduction 13 3530-3536.

Gerros TC, Semrad SD, Proctor RA \& LaBorde A 1993 Effect of dose and method of administration of endotoxin on cell mediator release in neonatal calves. American Journal of Veterinary Research 54 2121-2127.

Goelst K, Mitchell D \& Laburn H 1992 Fever responses in newborn lambs. Pflugers Archiv - European Journal of Physiology 421 299-301.

Gonçalves LF, Chaiworapongsa T \& Romero R 2002 Intrauterine infection and prematurity. Mental Retardation and Developmental Disabilities Research Reviews 8 3-13.

Grigsby PL, Hirst JJ, Scheerlinck J-P, Phillips DJ \& Jenkin G 2003 Fetal responses to maternal and intra-amniotic lipopolysaccharide administration in sheep. Biology of Reproduction 68 1695-1702.

Haudek SB, Natmessnig BE, Fürst W, Bahrami S, Schlag G \& Redl H 2003 Lipopolysaccharide dose response in baboons. Shock 20 431-436.

Jenkin G, Ward J, Hooper SB, O'Connor AE, de Kretser DM \& Wallace EM 2001a Feto-placental hypoxemia regulates the release of fetal activin A and prostaglandin E2. Endocrinology 142 963-966.

Jenkin G, Ward J, Loose J, Schneider-Kolsky M, Young R, Canny B, O'Connor A, de Kretser D \& Wallace E $2001 b$ Physiological and regulatory roles of activin A in late pregnancy. Molecular and Cellular Endocrinology 180 131-138. 
Jones KL, Brauman JN, Groome NP, de Kretser DM \& Phillips DJ 2000 Activin A release into the circulation is an early event in systemic inflammation and precedes the release of follistatin. Endocrinology 141 1905-1908.

Jones KL, de Kretser DM, Clarke IJ, Scheerlinck J-PY \& Phillips DJ 2004 Characterisation of the rapid release of activin A following acute lipopolysaccharide challenge in the ewe. Journal of Endocrinology 182 69-80.

Klein R, Robertson DM \& Clarke IJ 1996 Studies in sheep examining plasma follistatin elevations due to frequent blood sampling or surgery. Reproduction Fertility and Development $\mathbf{8}$ 273-277.

Knight PG, Muttukrishna S \& Groome NP 1996 Development and application of a two-site enzyme immunoassay for the determination of 'total' activin-A concentrations in serum and follicular fluid. Journal of Endocrinology 148 267-279.

LeMay DR, LeMay LG, Kluger MJ \& D’Alecy LG 1990 Plasma profiles of IL-6 and TNF with fever-inducing doses of lipopolysaccharide in dogs. American Journal of Physiology Regulatory, Integrative and Comparative Physiology 259 R126-R132.

Loose JM, Miller SL, Supramaniam VG, Ward JW, O'Connor AE, de Kretser DM, Wallace EM \& Jenkin G 2004 Hypoxia induced activin secretion by the fetoplacental unit: differential responses related to gestation. British Journal of Obstetrics and Gynaecology 11 1346-1352.

Medzhitov R 1998 An ancient system of host defense. Current Opinion in Immunology 10 12-15.

Mullington J, Korth C, Hermann DM, Orth A, Galanos C, Holsboer F \& Pollmä cher T 2000 Dose-dependent effects of endotoxin on human sleep. American Journal of Physiology - Regulatory, Integrative and Comparative Physiology 278 R947-R955.

Muttukrishna S 2001 Inhibin, activin and follistatin in human pregnancy. In Inhibin, Activin and Follistatin in Human Reproductive Physiology, pp 119-140. Eds S Muttukrishna \& W Ledger. London: Imperial College Press.
Phillips DJ 2003 The activin/inhibin family. In The Cytokine Handbook, 4th edn, vol 2, pp 1153-1177. Eds A Thomson \& MT Lotze. London: Academic Press.

Phillips DJ, Hedger MP, McFarlane JR, Klein R, Clarke IJ, Tilbrook AJ, Nash AD \& de Kretser DM 1996 Follistatin concentrations in male sheep increase following sham castration/castration or injection of interleukin-1 $\beta$. Journal of Endocrinology 151 119-124.

Robertson DM, Foulds LM, Prisk M \& Hedger MP 1992 Inhibin/activin $\beta$-subunit monomer: isolation and characterization. Endocrinology 130 1680-1687.

Sacks G, Sargent I \& Redman C 1999 An innate view of human pregnancy. Immunology Today 20 114-118.

Sanchez-Cantu L, Rode HN \& Christou NV 1989 Endotoxin tolerance is associated with reduced secretion of tumor necrosis factor. Archives of Surgery 124 1432-1436.

Schneider-Kolsky M, D’Antona D, Evans LW, Taylor N, O'Connor A, Groome NP, de Kretser D \& Wallace EM 2000 Maternal serum total activin A and follistatin in pregnancy and parturition. British Journal of Obstetrics and Gynaecology 107 995-1000.

Schneider-Kolsky ME, Tong S \& Wallace EM 2002 Maternal and foetal activin A levels: associations with normal and abnormal labour. Placenta 23 542-546.

Schröder HJ \& Power GG 1997 Engine and radiator: fetal and placental interactions for heat dissipation. Experimental Physiology 82 403-414.

Whyte RI, Warren HS, Greene E, Glennon ML, Robinson DR \& Zapol WM 1989 Tolerance to low-dose endotoxin in awake sheep. Journal of Applied Physiology 66 2546-2552.

Woodruff TK 1998 Regulation of cellular and system function by activin. Biochemical Pharmacology 55 953-963.

Received 27 October 2004

Accepted 10 January 2005 